친수성 표면 처리를 통한 공기 예열 열교환기의 응축 열전달 성능 연구

박재원 · 황승식* · 석성철 · 신동훈 · 정태용*† · 손승길**

국민대 대학원 기계공학과, ${ }^{*}$ 국민대학교 기계시스템공학부, ${ }^{* *}$ 경동나비엔

(2013년 11월 27일 접수, 2014년 7월 10일 수정, 2014년 7월 14일 채택)

\title{
A Study on Condensation Heat Transfer in Air Pre-heating Heat Exchanger using Hydrophilic Surface
}

Jae Won Park · Sueng Sik Hwang* - Sung Chul Seok • Dong Hoon Shin · Tae Yong Chung ${ }^{* \dagger} \cdot$ Sueng gil Son ${ }^{* *}$

Dept. of Mechanical Engineering, Graduate School of Kookmin Univ.,

*Dept. of Mechanical System Engineering, Kookmin Univ., ${ }^{* *}$ Kyung Dong Navien.

(Received 27 November 2013, Revised 10 July 2014, Accepted 14 July 2014)

요약

콘덴싱 보일러에 이용되는 공기 예열 열교환기에서의 열전달을 향상시키기 위해 전열면에 플라즈마 표면처리가 응축열전달에 미치는 영향에 대하여 연구하였다. 연구 결과 표면처리를 한 친수성 평판이 원판보다 약 $10 \%$ 의 열전달 증진을 보여주었다. 원판과 친수처리 평판에서 측정한 응축 열전달 계수를 Shah 상관식과 비교해 본 결과 Shah 상관식이 원판에서 측정한 응축 열전달 계수를 $10 \%$ 오차 범위로 잘 예측하는 것으로 나타났다. 따라서, 원판을 이용한 공기예열 열교환기를 설계할 때 Shah 상관식이 이용될 수 있음을 본 연구에서 알 수 있었다.

주요어 : 공기 예열 열교환기, 응축 열전달, 친수성

\begin{abstract}
To increase the heat transfer rate of the air pre-heating heat exchanger used for the condensing boiler, We investigated condensation heat transfer coefficients through plasma surface treatment. The hydrophilic surface showed about $10 \%$ increase in heat transfer rate than original plate. It shows that Shah correlation can be used to predict the condensation heat transfer coefficient on the original surface within $10 \%$ error range after the compatison between Shah correlation and the condensation heat transfer coefficients measured on the hydrophilic surface and original surface. Therefore, we have shown that Shah correlation is available when designing the air pre-heating heat exchanger using the original surface in this study.
\end{abstract}

Key words : Pre-heating heat exchanger, Condensation heat transfer, Hydrophilic

\section{1. 서 론}

현재 상용화되어 시판중인 콘덴싱 보일러 (condensing boiler)는 보일러 효율을 높이기 위해 배 출가스에 포함된 수증기의 잠열 에너지를 연소용 공

\footnotetext{
${ }^{\dagger}$ To whom corresponding should be addressed. Dept. of Mechanical System Engineering Kookmin Univ., Jeongneung 3-dong, Seongbuk-gu, Seoul 136-702, Korea Tel : 02-910-4674 E-mail : tychung@kookmin.ac.kr
}

기가 회수한다. 이 때, 공기 예열 열교환기는 배출가 스에 포함된 수증기를 포화온도 이하로 낮추어, 응축 된 수증기의 잠열을 회수하는 역할을 한다.

공기 예열 열교환기의 배출가스 측 표면에서는 외 기에 의해 배기가스에 포함된 수증기가 포화온도 이 하로 냉각된 표면과 만나 응축이 발생한다. 이때의 열전달 계수는 단상(single phase)의 기체일 때 보다 높은 열전달 계수를 갖는다. A. F. Mills ${ }^{[1]}$ 는 표면의 거 친 부분에서 액적응축이 시작되어 액적들끼리 합쳐지면 
서 급속히 성장하다가 중력에 의해 표면을 흘러내리는 과정이 계속 반복되는 응축이 발생한다고 보고하였다. 이 때, 열교환기는 매우 높은 응축 열전달 성능을 가진다.

열교환기에서 열전달계수가 커지면 열교환기 크기 를 줄여 소형화시킬 수 있고, 제작비용을 절감할 수 있다. 이러한 이점 때문에 최근 이상(two-phase)유체 의 열전달에 관한 연구들이 많이 진행되고 있다. 또 한, 열교환기 표면처리를 통해 젖음성을 변화시켜 액 적응축 또는 막응축 현상 증진을 통해 열전달 성능을 보다 높게 만드는 연구도 활발히 수행 중이다. $\mathrm{Ma}$ 등 [2]은 구리와 알루미늄으로 만들어진 수직 평판에 fluorocarbon 유기물을 코팅하여 응축열전달을 연구 한 결과, 액적응축일 때 열전달이 증진됨을 보고하였 다. $\mathrm{Li}$ 등[3] 은 티타늄으로 만들어진 수직 평판에 hydrofluoric 산화 처리를 하여 액적의 접촉각이 작게 된 판과 과산화수소 처리를 하여 접촉각이 크게 된 판에서 응축열전달을 연구한 결과, 과산화수소 처리 를 하여 접촉각이 크게 된 티타늄 판에서 열전달이 증가됨을 제시하였다.

열교환기의 표면처리는 보통 플라즈마 처리가 광 범위하게 이용되고 있다. 나노 임프린트, 나노 사출성 형 등의 경제적이면서도 대량 생산이 가능한 마이크 로/나노 구조 가공기술은 거친 표면을 제조하는데 있 어 쉽게 응용될 수 있는 기술이지만, 아직 이러한 기 술은 큰 면적에 나노급의 구조물을 만들기에는 기술 적인 한계를 가지고 있다. 반면 플라즈마를 통한 고 분자 식각기술은 잘 정렬된 표면을 만들지는 못하지 만, 거친 표면을 만들어 표면을 친수화 하는 데는 적 합하다. 플라즈마 처리와 관련하여 $\mathrm{Ahn}$ 등[4]은 알루 미늄 표면에 대해 계면활성제와 플라즈마 처리에 의 한 코팅 성능 변화에 대해 경시변화가 거의 없다는 결론을 내렸다. Shen 등[5] 은 스테인레스 강 표면에 대하여 상압 플라즈마 처리 시간과 전압 강도가 증가 함에 따라 접촉각이 친수에 가까워 진다는 결론을 내 렸다. Kim 등[6]은 스테인레스 강 표면에서 상압 플라 즈마 처리 속도와 노즐과 스틸 표면의 간극이 증가함 에 따라 접촉각이 증가하는 것을 보였고 플라즈마 처 리 직후 90 시간 이후부터 접촉각이 안정화 상태가 되 는 것을 보였다.

본 연구에서는 열교환기 재질 표면을 $O_{2}$ 상압 플 라즈마를 이용하여 친수화 처리를 하였다. 친수처리 된 평판과 친수처리 되지 않은 원판에 대해 실험적 연구를 통하여 응축열전달 증진에 대해 연구하였다.
2. 이론적 고찰.

2-1. 실험을 통한 응축 열전달계수 고찰

열교환기 고온부에서 저온부로 전달되는 열량은 저온부 냉각수가 흡수한 열량과 같으므로 열전달량 $q$ [ $W]$ 는 식 (1)로 구하였다.

$$
q=m_{w} C_{p, w}\left(T_{w, \text { outlet }}-T_{w, \text { inlet }}\right)
$$

여기서 $m_{w}[\mathrm{~kg} / \mathrm{s}]$ 은 저온부를 흐르는 냉각수 유 량, $\quad C_{p, w}[\mathrm{~kJ} / \mathrm{kg} \cdot \mathrm{K}]$ 는 냉각수의 비열값이다. $T_{w, \text { outlet }}$ 과 $T_{w, \text { inlet }}$ 은 각각 저온부측 냉각수의 출구 및 입구 온도 $\left[{ }^{\circ} \mathrm{C}\right]$ 이다.

열전달판을 통한 고온부에서의 저온부로의 평균 종합 열전달계수 $U\left[W / m^{2} / K\right]$ 는 식 (2)와 같이 나 타낼 수 있다.

$$
U=\frac{q}{A \triangle T_{l m}}
$$

여기서 $\mathrm{A}\left[m^{2}\right]$ 은 고온부 측 유체와 저온부 측 유체 사이에서 열전달이 일어나는 전열면적이다. 대수평균 온도차 $\triangle T_{l m}\left[{ }^{\circ} \mathrm{C}\right]$ 은 식 (3)과 같다.

$$
\Delta T_{l m}=\frac{\left(T_{v+g, \text { outlet }}-T_{w, \text { inlet }}\right)-\left(T_{v+g, \text { inlet }}-T_{w, \text { outlet }}\right)}{\ln \frac{\left(T_{g+a, \text { outlet }}-T_{w, \text { inlet }}\right)}{\left(T_{g+a, \text { inlet }}-T_{w, \text { outlet }}\right)}}
$$

여기서 $T_{g+a, \text { inlet }}\left[{ }^{\circ} \mathrm{C}\right]$ 과 $T_{g+a, \text { outlet }}$ 은 고온부 측의 수증기를 포함한 공기의 입구 및 출구 온도이다. 고온부측 응축 열전달계수는 식 (4)로 구한다.

$$
h_{g+a}=\frac{1}{\frac{1}{U}-\frac{l_{\text {plate }}}{k_{\text {plate }}}-\frac{1}{h_{w}}}
$$

여기서 $l[m]$ 은 실험에 사용된 시편인 STS430 평 판의 두께이고, $k[\mathrm{~W} / \mathrm{m} / \mathrm{K}]$ 는 STS430 평판의 열전 도율이다. $h_{w}\left[W / m^{2} / K\right]$ 는 냉각수 측의 대류열전달 계수이다. 
냉각수 측 대류열전달계수 $h_{w}$ 는 본 실험에서 이루 어진 $R a_{L}$ 값이 속하는 $10^{-1}<R a_{L}<10^{9}$ 에서 잘 맞는 것으로 알려진 식 (5)를 이용하여(13) 계산하여 구하였다.

$$
N u=\frac{h_{w} L_{c}}{k_{w}}=\left\{0.825+\frac{0.387 R a_{L}^{1 / 6}}{\left[1+(0.492 / \operatorname{Pr})^{9 / 16}\right]^{8 / 27}}\right\}^{2}
$$

$\operatorname{Pr}[-]$ 은 $C_{p, w} \mu_{w} / k_{w}$ 로 표현되는 Prandtl 무차원수 이며 $R a_{L}$ 는 Reyleigh 수이다.

\section{2-2. 상관식을 통한 응축 열전달계수 고찰}

수증기가 응축되는 열전달 계수는 표 1에 나타낸 일반적으로 광범위하게 응축 문제에 적용되고 있는 $\operatorname{Shah}(1979)^{(9)}$, Shah(2009) ${ }^{(10)}$, Travaiss(1973) ${ }^{(11)}$ 을 이 용하여 예측하였다.

$\operatorname{Shah}(1979)^{(9)}$ 는 광범위한 실험자료를 기반으로 Dittus-Boeltus 식을 변형하여 다양한 작동유체에 적용 될 수 있는 응축열전달 실험 상관식을 제시하였다. 그러나, $\operatorname{Shah}(1979)^{(9)}$ 상관식은 질량면속이 200 $\mathrm{kg} / \mathrm{m} 2 / \mathrm{s}$ 이상인 큰 유량에서는 응축열전달을 잘 예측 하는 것으로 많은 문헌에서 보고되고 있으나, 작은 유량에서는 응축열전달을 잘 예측하지 못한다. 이에 따라 최근 $\operatorname{Shah}(2009)^{(10)}$ 는 $\Phi 2 \sim 49 \mathrm{~mm}$, 질량면속 4 $\sim 820 \mathrm{~kg} / \mathrm{m} 2 / \mathrm{s}$, 환산압력(reduced pressure) $0.0008 \sim$ 0.9 범위에서 예측이 가능한 상관식을 제안하였다.

실험 결과를 상관식으로 예측하기 위하여 건도 $x$ 와 Lockhart-Martinelli parameter 값 $X_{t t}$ 및 물성치는 고온부와 저온부의 평균값을 이용하여 구하였다. 건
도 $x$ 는 식 (6)을 통하여 구하였고 입구의 건도와 출구 의 건도값의 평균값을 이용하여 상관식에 대입하였다.

$$
\begin{aligned}
& x=\frac{m_{g}}{m_{\text {total }}} \\
& m_{\text {total }}=m_{g}+m_{w}
\end{aligned}
$$

여기서 $m_{g}[\mathrm{~kg} / \mathrm{s}]$ 는 공기속에 포화된 수증기의 양 이다. $m_{t o t a l}[\mathrm{~kg} / \mathrm{s}]$ 은 식 (7)과 같이 수증기와 물의 혼합물의 양이다. 하지만 입구영역에서 공기속에 포 화된 수증기의 상태는 $100 \%$ 수증기 상태이므로 건도 $x$ 는 1 이다. 반면 출구영역에서는 저온부에 의한 냉각 으로 수증기의 일부가 물로 상변화를 일으킨다. 따라 서 상변화로 생성된 물의 양을 계산하기 위해 입구영 역의 온도조건에서 공기속에 포화된 수증기의 질량유 량과 출구영역의 온도조건에서 공기속에 포화된 수증 기의 질량유량 차를 이용하여 냉각에 의한 상변화로 생성되는 물의 질량유량을 식 (8)을 이용하여 구하였 다.

$$
m_{w}=m_{g, \text { inlet }}-m_{g, \text { outlet }}
$$

여기서 $m_{w}[\mathrm{~kg} / \mathrm{s}]$ 는 냉각에 의한 상변화로 생성되 는 물의 질량유량이다. 입구영역과 출구영역에서 공 기 속에 포화된 수증기의 양을 계산하기 위해 식 (9) 와 식 (10)을 이용하여 구하였다.

$$
m_{g, \text { inlet }}=m_{g+a} \times \omega_{\text {inlet }}
$$

Table 1. Existing correlation equations of condensaton heat transfer coefficient

\begin{tabular}{c|l}
\hline Shah(1979) & $h_{T P}=\left[(1-x)^{0.8}+\frac{3.8 x^{0.76}(1-x)^{0.04}}{\left(P_{a t} / P_{c r}\right)^{0.38}}\right] \times h_{L T}$ \\
& $h_{L T}=0.023\left(\frac{k_{w}}{D}\right)\left(\frac{G_{g} D}{\mu_{w}}\right)^{0.8} \operatorname{Pr}_{w}^{0.4}$ \\
\hline Shah(2009) & $h_{I}=h_{L T}\left(\frac{\mu_{w}}{14 \mu_{v+a}}\right)^{0.0058+0.557 P_{a t} / P_{c r}} \times\left[(1-x)^{0.8}+\frac{3.8 x^{0.76}(1-x)^{0.04}}{\left(P_{a t} / P_{c r}\right)^{0.38}}\right]$ \\
\hline Traviss(1973) & $h=\left(\frac{k_{w}}{D}\right) \frac{0.15 \operatorname{Pr}_{w}}{F_{t}}\left(\frac{(1-x) D}{\mu_{w}}\right)^{0.9}\left[\frac{1}{X_{t t}}+\frac{2.85}{X_{t t}^{0.476}}\right]$ \\
\hline
\end{tabular}

$x$ 는 건도, $P_{a t} / P_{c r}$ 은 환산압력, $G\left[k g / m^{2} / s\right]$ 는 질량면속, $D[m]$ 는 수력지름, $\mu\left[N s / m^{2}\right]$ 은 점성계수, $X_{t t}$ 는 Lockhart-Martinelli parameter 이다. 


$$
m_{g, \text { outlet }}=m_{g+a} \times \omega_{\text {outlet }}
$$

여기서 $m_{g+a}[\mathrm{~kg} / \mathrm{s}]$ 는 고온부 측에 공급되는 수 증기를 포함한 공기의 질량유량이고 $\omega[\mathrm{kg} / \mathrm{kg}]$ 는 절 대습도이다. 절대습도는 입구영역의 온도에 해당하는 절대습도와 출구영역의 온도에 해당하는 절대습도를 식 (11)을 통하여 구하였다.

$$
\omega=0.622 \times \frac{P_{v}}{P_{a}}=0.622 \times \frac{P_{g}}{P_{a}}
$$

여기서 $P_{v}$ 는 해당하는 영역에서의 온도에 대한 수 증기의 부분압력 이고 $P_{a}$ 은 건공기의 부분압력이다. 수증기의 부분 압력 $P_{v}$ 는 상대습도 $100 \%$ 일 때 포화 압력 $P_{g}$ 를 대입하여 구할 수 있다. 따라서 본 연구에 서는 입출구 영역에서 상대습도가 $100 \%$ 이기 때문에 물의 포화압력 $P_{g}$ 를 사용하였다. 건공기의 부분압력 $P_{a}$ 는 식 (12)를 이용하여 구하였다.

$$
P_{a}=P-P_{v}
$$

압력 $P$ 는 총 압력이다. 따라서 이 압력값은 입구 영역과 출구영역에서 측정된 압력값을 사용하였다. 실험결과 평균적으로 입구에서는 $101.4 \mathrm{kpa}$, 출구에서 는 대기압으로 측정되었다.

Lockhart-Martinelli parameter 값인 $X_{t t}$ 값은 식 (13)에 의해 계산된다.

$$
X_{t t}=\frac{m_{w}}{m_{g}} \sqrt{\frac{\rho_{w}}{\rho_{g}}}
$$

여기서 $m_{w}$ 값은 식 (8)에서 계산된 값을 이용하였 고 $m_{g}$ 는 입구영역 수증기의 질량유량과 출구영역에 서 수증기의 질량유량 값을 이용하였다. 또한 밀도값 $\rho$ 는 입출구 온도의 평균값에 대한 밀도값을 이용하 여 계산하였다.

\section{3. 실험방법.}

\section{3-1. 실험 시편.}

상용화된 콘덴싱 보일러에서는 수명을 증진시키기
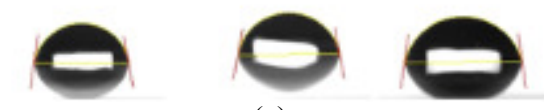

(a)

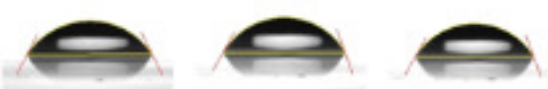

(b)

Fig. 1. Photograph of measured contact angle on both original and hydrophilic plate

Table 2. Measured value of contact angle

\begin{tabular}{c|c|c|c|c}
\hline & $1 \mathrm{st}$ & 2nd & 3rd & Average \\
\hline \hline $\begin{array}{c}\text { Original } \\
\text { surface }\end{array}$ & $80.56^{\circ}$ & $79.16^{\circ}$ & $81.97^{\circ}$ & $80.56^{\circ}$ \\
\hline $\begin{array}{c}\text { Hydrophilic } \\
\text { surface }\end{array}$ & $63.11^{\circ}$ & $64.1^{\circ}$ & $65.23^{\circ}$ & $64.15^{\circ}$ \\
\hline
\end{tabular}

위해 부식이나 내식성이 강한 재질인 STS430 스테인 리스 강이 이용되고 있다. 따라서 공기 예열 열교환 기 응축 열전달 실험에 이용된 시편의 재질은 STS430 스테인리스 강을 사용하였다. STS430 평판 의 크기는 가로 $80 \mathrm{~mm}$, 세로 $210 \mathrm{~mm}$, 두께 $0.6 \mathrm{~mm}$ 이다. 평판의 친수화 처리를 위해 $\mathrm{APP}$ 사의 $\mathrm{O}_{2}$ 상압 플라즈마 장비를 이용하였다. 표면처리를 위해 상압 플라즈마에 평판을 노출시킨 조건은 속도 $20 \mathrm{~mm} / \mathrm{s}$, 왕복거리 $400 \mathrm{~mm}$, 왕복횟수 $1 \mathrm{cycle}$ 의 조건으로 노출 시켰다. 그림 1(a)는 STS430판에 $O_{2}$ 상압 플라즈마 를 처리하기 전의 임의의 3 군데 영역에 물방울의 접 촉 형상을 보여주며, 그림 1(b)는 $O_{2}$ 상압 플라즈마 처리 후의 $\mathrm{Kim}$ 등[6] 의 연구에 근거하여 90 시간 이 후 측정된 접촉각을 보여준다.

표 2 는 그림 1 에 나타낸 물방울의 접촉각과 평균 값을 나타낸 것이다. $O_{2}$ 상압 플라즈마 처리 후 물방 울의 접촉각이 작아지는 것을 알 수 있다. 따라서, $O_{2}$ 상압 플라즈마 처리 후 STS430 평판에 친수성이 약 $20 \%$ 증진되는 것을 알 수 있었다.

3-2. 실험 장치 및 조건.

그림 2는 공기 예열 열교환기의 응축 열전달계수 측정의 실험 장치의 개략도를 나타낸 것이다. 콘덴싱 보일러의 배출가스를 모사하기 위해 본 실험에서는 작동유체로 수증기가 포함된 공기를 이용하였다. 표 3 은 실험 장치에 이용된 실험장비의 제원을 나타낸 것 


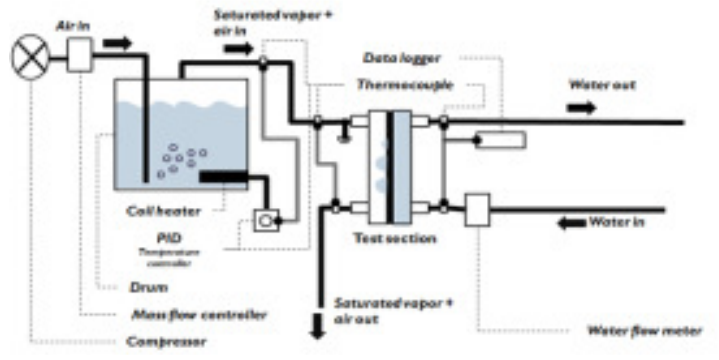

Fig. 2. System diagram of experimental setup

이다. 수증기가 포함된 공기의 생성은 $2 k W$ 코일 히 터가 장착된 알루미늄 재질의 탱크 내부에서 물을 끓 인 후 공기 압축기로 탱크에 공기를 주입하여 수증기 가 포함된 공기를 생성하였다. 수증기가 포함된 공기 의 유량 조절을 위해 SIERA사 $100 \mathrm{lpm}$ 가스 유량 조절기를 공기가 주입되는 입구에 설치하였다. 생성 된 수증기가 포함된 공기는 수직 대향류 열교환기의 고온부로 주입된다. 열교환기 고온부 입구에 온도제 어장치를 장착하여 열교환기 고온부로 들어가는 수증 기가 포함된 공기의 온도를 $80^{\circ} \mathrm{C}$ 로 설정하였고 열교 환기의 고온부와 저온부의 입출구 온도 측정 및 기록 은 YOKOGAWA사 MV2000 모델을 이용하여 기록 하였다. 현재 $\mathrm{K}$ 사에서 개발중인 $30000 k W$ 급 콘덴싱 보일러 공기 예열 열교환기의 고온부에 주입되는 배 출가스의 Reynolds 수는 대략 800정도이다. 따라서, 본 실험에 사용되는 열교환기의 응축 열전달 성능 평 가를 위해 Reynolds수 800(실험장치 기준 $17 \mathrm{lpm}$ )을 기준으로 표 4와같이 실험조건을 설정하였다.

열교환기 저온부에는 열회수를 위해 작동유체로 물을 사용하였다. 공기 예열 열교환기에서는 열회수 를 위해 연소용 외부 공기가 이용되나 본 실험에서는 고온부 측의 응축 열전달 계수에 관한 연구이기 때문 에 실험의 편리성으로 물을 사용하였다. 고온부에서

Table 3. Experimental equipment specification

\begin{tabular}{c|c|c}
\hline \multirow{2}{*}{$\begin{array}{c}\text { Ball flow } \\
\text { meter }\end{array}$} & Company & Dwyer instruments \\
\cline { 2 - 3 } $\begin{array}{c}\text { Heat } \\
\text { exchanger }\end{array}$ & Model & RMA-2 \\
\cline { 2 - 3 } & Material & Polycarbonate \\
\hline \multirow{2}{*}{$\begin{array}{c}\text { Data } \\
\text { logger }\end{array}$} & Company & $20 \times 5 \times 200 \mathrm{~mm}$ \\
\cline { 2 - 3 } & Model & YOKOGAWA \\
\hline \multirow{2}{*}{$\begin{array}{c}\text { Thermo- } \\
\text { couple }\end{array}$} & Company & GE-SEVEN \\
\cline { 2 - 3 } & Type & T \\
\cline { 2 - 3 } & Size & $\Phi 1.6 m m$ \\
\hline \multicolumn{2}{c}{ RMS error } & $\pm 0.76 \%$ \\
\hline
\end{tabular}

냉각되는 열량을 감안하여 저온부 입출구 온도차는 평균 $15^{\circ} \mathrm{C}$, 유량은 $0.00133 \mathrm{~kg} / \mathrm{s}$ 로 설정하였다.

\section{4. 결 과}

그림 3 은 공기 예열 열교환기에 원판과 친수처리 평판을 이용하였을 경우 식(2)에 의해 계산된 평균 종합 열전달계수값을 나타낸 것이다. 각 실험조건에 서 약 30 분이 지나면 정상상태에 도달하며, 정상상태 의 데이터 획득을 위해 각 유량에서 5 분간 온도를 계 측하여 평균값을 산출하였다. 이러한 방식으로 각 유 량에 대해서 동일한 작동조건으로 9 13개의 실험 데이터를 획득하여 평균값으로 그래프에 나타내었다. 실험 결과 원판과 친수처리 평판에서 수증기가 포함 된 공기의 유량이 증가할수록 응축 열전달계수도 증 가한다.

친수처리 평판은 원판보다 응축 열전달계수가 약 $10 \%$ 정도 증가되는 것을 실험을 통해 확인할 수 있 었다. 이는 열교환 면적 전체에서 발생하는 응축에 의한 영향 때문인 것으로 사료된다. 접촉각이 원판에 비해 작은 친수성 평판의 경우 응축의 두께가 작기 때문에 원판에 비해 응축에 의한 저항이 작다. 또한 응축이 발생하면서 전열면과 접촉면이 넓기 때문에 더 많은 열을 전달할 수 있다.

그림 4 를 통하여 냉각수 출구의 온도는 친수성 평 판이 원판에 비해 보통 $1 \sim 2{ }^{\circ} \mathrm{C}$ 정도 높게 측정되는 것을 확인 할 수 있었다. 이는 친수성 평판이 원판보 다 고온부의 잠열을 더 잘 회수한다는 것을 의미한다.

그림 5 는 원판 고온부에서의 실험에 의한 응축 열 전달계수와 상관식에 의한 응축 열전달 계수를 비교 한 것이다. Shah(1979) $)^{(9)}$ 상관식과 $\operatorname{Shah}(2009)^{(10)}$ 상 관식의 경우 유량이 $10 \sim 14 \mathrm{lpm}$ 에서 실험값보다

Table 4. The experimental condition

\begin{tabular}{c|c|c}
\hline $\begin{array}{c}\text { vapor } \\
+ \text { air }\end{array}$ & $\begin{array}{c}\text { Inlet temperature, } \\
\left.T_{v+a}{ }^{\circ} \mathrm{C}\right]\end{array}$ & 80 \\
\hline \multirow{2}{*}{ Air } & $\begin{array}{c}\text { Volume flow rate, } \\
Q[\mathrm{lpm}]\end{array}$ & $\begin{array}{c}10,12,14,15, \\
16,18,20\end{array}$ \\
\hline \multirow{5}{*}{ Water } & $\begin{array}{c}\text { Inlet temperature, } \\
T_{w}\left[{ }^{\circ} \mathrm{C}\right]\end{array}$ & 15 \\
\cline { 2 - 3 } & $\begin{array}{c}\text { Mass flow, } \\
m_{w}[\mathrm{~kg} / \mathrm{s}]\end{array}$ & 0.00133 \\
\hline
\end{tabular}




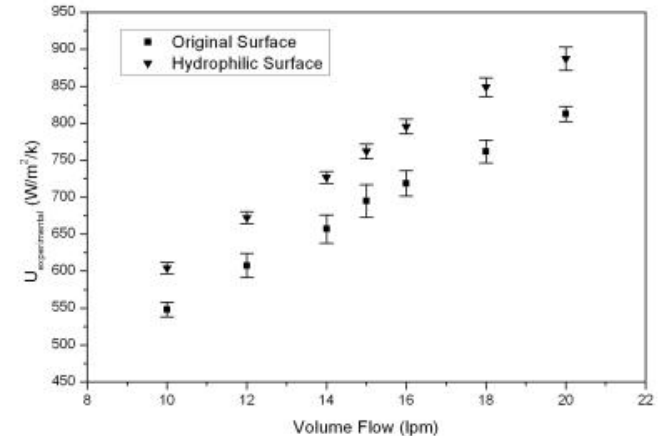

Fig. 3. Comparison of heat transfer coefficient for original and hydrophilic surfaces

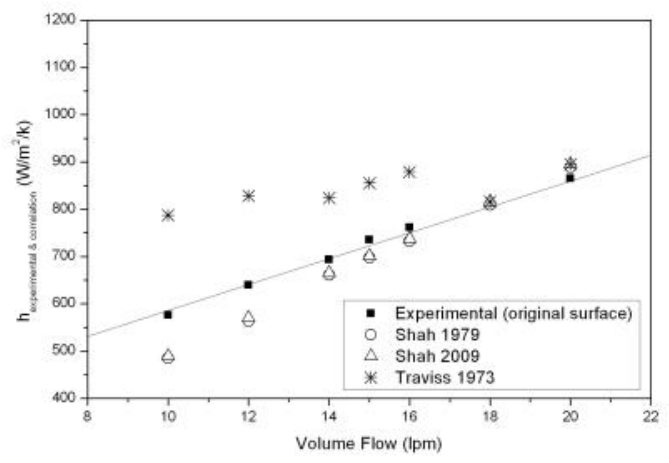

Fig. 5. Comparison of experimental heat transfer data of original surface and predicted heat transfer coefficient of correlations

낮은 값을 보이나, $15 \mathrm{lpm}$ 이후부터 실험값과 비슷하 게 일치하는 경향을 보인다. Traviss(1973) ${ }^{(11)}$ 상관식 의 경우 유량이 $18 \sim 20 \mathrm{lpm}$ 에서 일치하는 경향을 보 이나, 유량이 10 16lpm 일 때 실험값의 경향과는 거 리가 있다고 판단된다. 본 연구에서 수증기의 질량면 속은 최대 $1.25 \mathrm{~kg} / \mathrm{m}^{2} / \mathrm{s}$ 최소 $0.62 \mathrm{~kg} / \mathrm{m}^{2} / \mathrm{s}$ 이다. 결과적으로 $\operatorname{Shah}(1979)^{(9)}$ 와 $\operatorname{Shah}(2009)^{(10)}$ 는 본 실험 의 질량면속 범위에서는 큰 차이가 나지 않는 것을 확인하였다. Shah 상관식으로 원판의 응축 열전달계 수를 계산하였을 때 그림 5 와 같이 실험치를 약간 높 게 예측한다. 상대적으로 원판과 친수처리 평판을 비 교하였을 때 친수처리 평판의 응축 열전달계수를 Shah 상관식으로 잘 예측할 수 있는 것으로 본 연구 를 통해 확인하였다.

상관식을 이용하여 계산한 원판에서의 응축 열전 달계수와 친수성 평판에서의 응축 열전달계수는 거의 같은 것을 확인할 수 있었다. 이는 단지 수증기가 포 함된 공기의 입출구 온도만을 가지고 응축 열전달계

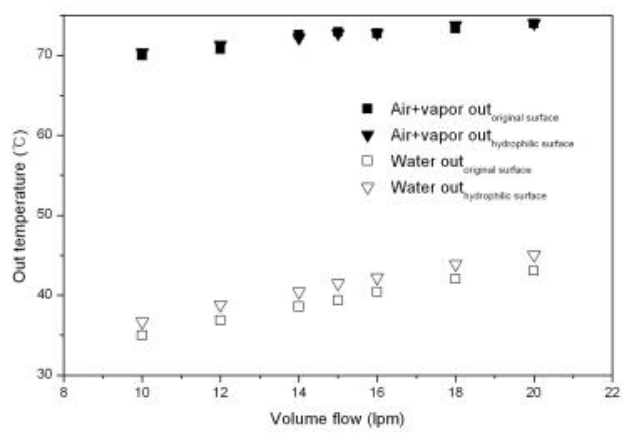

Fig. 4. comparison of outlet temperature from hot side and cool side in hydrophilic surface and original surface of experimental

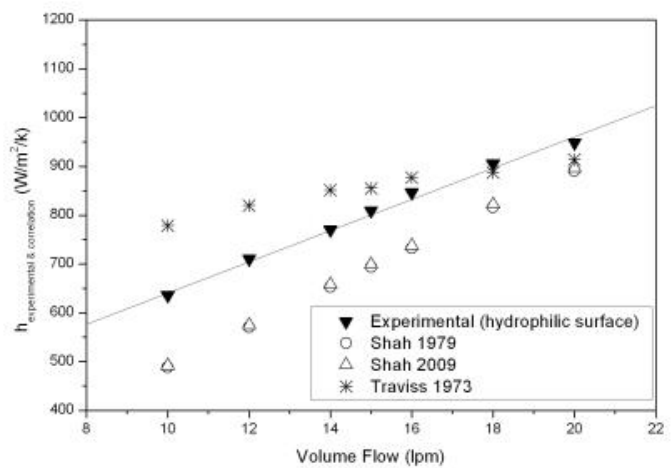

Fig. 6. Comparison of experimental heat transfer data of hydrophilic surface and predicted heat transfer coefficient of correlations

수를 계산하기 때문이다. 하지만 실험 결과를 바탕으 로 식 (4)를 이용하여 계산한 응축 열전달계수의 경 우 냉각수 측의 온도차를 이용하여 열전달량 값을 구 하기 때문에 원판과 친수성 평판의 응축 열전달계수 값이 차이가 난다고 할 수 있다.

\section{5. 결 론}

친수처리 전열면에 이루어진 응축 열전달 계수에 미치는 영향을 고찰하기 위하여 그림 2의 실험장치의 수직 대향류 열교환기에 원판과 친수처리 평판을 장 착하여 열전달 실험을 수행하여 다음과 같은 결론을 얻었다.

(1) 실험 결과 친수처리 평판을 잠열회수 열교환기 에 이용한 경우 응축 열전달계수가 약 $10 \%$ 증 진되는 것을 확인하였다.

(2) 원판과 친수처리 평판에서 측정한 응축 열전달 계수를 Shah 상관식과 비교해 본 결과 Shah 상 
관식이 원판에서의 응축 열전달 계수를 $(10 \%)$ 오차 범위로 잘 예측하는 것으로 나타났다. 따 라서, 원판을 이용한 공기예열 열교환기를 설계 할 때 Shah 상관식이 이용될 수 있음을 확인 하였다.

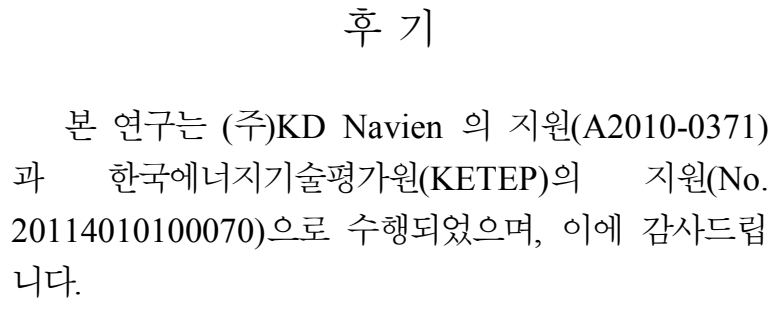

\section{References}

1. A. F. Mills., 2003, Basic Heat and Mass Transfer, Pearson Education, New Jersey, pp. 536-537

2. Xue-H. M., Xing-D. Z., Zhong L., Yi-M. L. and Yu Z., 2008, "Condensation heat transfer enhancement in the presence of non-condensable gas using the interfacial effect of dropwise condensation," Int.J.Heat mass transfer, Vol.51, No.7-8, pp.1728 1737

3. Qi B., Zhang L., Xu H. and Sun Y., 2011, "Experimental study on condensation heat transfer of steam on vertical titanium plates with different surface energies," Exp. Ther. Fluid Sci.,Vol35, No.1,pp.211 218.

4. Ahn S. P., Jeong Y. M. and Ha S. C., 2001, "The Study on the Wetting Durability of Finned Tube Heat Exchangers for Various Coated Surfaces, " Proceedin go $\mathrm{f}$ ha-gye Symposium on the SAREK, pp.324 329

5. Shen T., Kwon O. J., Na L. and Choi H. S., 2004, "Surface Free Energy Changes of Stainless Steel after One Atmospheric Pressure Plasma Treatment" Kor.J.Chem.Eng.,Vol21,No.6,pp.1218 1223.

6. Kim M. C., Song D. K., Shin H. S., Baeg S. H., Kim G. S., Boo J. H., Han J. G., Yang S. H., 2003, "Surface modification for hydrophilic property of stainless steel treated by atmospheric-pressure plasma jet," Surface and coatings Technology, Vol.171, No.1-3, pp.312 316

7. Lee H. S., Jeon D. S., Kim Y. L. and Kim S. C., 2010, "Experimental Study of Evaporative Heat Transfer Characteristics of R-134a with Channel-Bending Angle in Microchannel Heat Exchangers," Trans. of the KSME(B),Vol.34,No.6,pp.635 642

8. W. M. Kays and M. E., 1993, Crawford Convection Heat and Mass Transfer 3rded,McGraw-Hill,NewYork,pp.125-126

9. Shah, M. M., 1979, “A general correlation for heat transfer during film condensation in pipes,” Int.J.Heat transfer.Vol.22 ,No.4, pp. 547-556

10. Shah, M. M., 2009, "An Improved and Extended General Correlation for Heat transfer During Condensation in Plain Tubes," Int HVAC\&R Research.Vol.15,No.5,pp.889-913

11. Traviss, D. P, W.M. Rohesenow, and A.B. Baron., 1973, "Forced convection condensation inside tubes: A heat transfer equation for condenser design," ASHRAE Transactions 79(1):157-65

12. Incropera., Dewitt., Bergman., Lavine., 2008, Introduction to Heat Transfer, WILEY, New Jersey, pp. 707

13. Yanus A. Cengel., 2011, Heat Transfer : A Practical Approach, Mc Graw Hill, New York, pp. 427 429

14. Baik Y. J., Chang Y. S., Kim Youngil., 2000, "Measurement of Single Phase and Condensation Heat Transfer Coefficient of Ammonia in a Horizontal Tube," 설비공학회 논문집, 제12권, 제6호, pp. 561-569 